\title{
Saberes para ensinar problemas: uma análise dos artigos da Revista de Educação (São Paulo, 1933-1943)
}

Andréia Fernandes de Souza

\section{Resumo}

Neste texto foram analisados os artigos da Revista de Educação publicados entre 1933 e 1943 que tratavam do ensino de aritmética, mais especificadamente o ensino de problemas aritméticos. $\mathrm{O}$ objetivo deste trabalho é identificar que saberes eram necessários e disseminados para o ensino de problemas aritméticos. Tais saberes, neste estudo são considerados como saberes profissionais do professor que ensina matemática. Como resultado observou-se que os autores lançavam mão do conhecimento de autores de referência pedagógica e/ou psicológica para justificar seus discursos para o ensino de aritmética. E nesta situação os saberes identificados para o ensino de problemas aritméticos foram a utilização de materiais didáticos como contador mecânico e jogos, os problemas a partir dos Centros de Interesse e os projetos, entendimento do programa de ensino, aumento do grau de dificuldade dos conteúdos e o domínio de múltiplos autores, tanto da área matemática, quanto da área pedagógica e psicológica.

Palavras-chave: Problemas aritméticos. Revistas pedagógicas. Saberes profissionais. 


\title{
Knowledge to teach problems: analyzing articles from Revista de Educação (São Paulo, 1933-1943)
}

\author{
Andréia Fernandes de Souza
}

\section{Abstract}

In this study, we analyzed articles from Revista de Educação (Education Journal, in free translation) published between 1933 and 1943, which approached the teaching of arithmetic with focus on the teaching of arithmetic problems. The aim of this paper is to identify what knowledge was necessary and disseminated for the teaching of arithmetic problems. In our research, such knowledge is understood as professional knowledge shared by educators who teach mathematics. As a result, we observed that the authors of the articles in the journal made use of knowledge supported by authors of reference in pedagogy and in psychology to justify their arguments for the teaching of arithmetic. In conclusion, the knowledge for the teaching of arithmetic problems that we have identified in this study involved teaching resources like mechanical counters and games, problems from centers of interest and projects, understanding of teaching programs, increasing the difficulty level of contents and mastery of various authors in the fields of mathematics, education and psychology.

Keywords: Arithmetic Problems. Education Journals. Professional knowledge 


\section{Introdução}

Este artigo tem como objetivo apresentar as primeiras análises da pesquisa de doutorado em andamento intitulada "Problemas aritméticos e o saber profissional do professor que ensina matemática (São Paulo, 1890-1990)”69. Esta pesquisa está inserida em um projeto maior70 e tem como questão investigar as mudanças nos saberes profissionais que o professor deveria possuir para ensinar problemas de aritmética ao longo desse período

Entendemos esses saberes profissionais a partir das pesquisas feitas por Hofstetter e Schneuwly (2017), na qual definem como sendo os saberes próprios da profissão distintos dos saberes de cultura geral. Os saberes profissionais são a articulação entre os saberes a ensinar e os saberes para ensinar, de modo simplificado são os saberes derivados do campo disciplinar, no caso aqui especificamente a matemática, articulados com os saberes do campo das Ciências da Educação.

$\mathrm{Na}$ tentativa de responder a questão colocada anteriormente se faz necessário observar os processos e dinâmicas para a construção dos saberes profissionais desde as reformas educacionais ocorridas nos anos finais do século XIX até a década de 1990 com a elaboração da LDBEN e dos PCNs marco temporal do projeto maior. Nessa pesquisa coletiva que vem sendo desenvolvida pelo GHEMAT ${ }^{71}$ "[...] é possível considerar etapas como: recompilação de experiências docentes, análise comparativa dos conhecimentos docentes, sistematização e uso dos conhecimentos como saberes." (VALENTE, 2018, p. 380)

Em busca dos primeiros resultados parciais da tese de doutorado, que corroboram para o projeto maior, serão analisados ao longo da pesquisa revistas pedagógicas publicadas no estado de São Paulo de 1890 até 1990. Levando em conta o estágio inicial do trabalho, apresentaremos neste texto uma primeira análise a partir da leitura dos artigos que tratam sobre o tema aritmética publicados na "Revista de Educação" entre 1933 e 1943, período de circulação desse periódico.

\section{Revista de Educação: o que diziam os artigos sobre o ensino de problemas aritméticos?}

Em pesquisa realizada por Souza (2017) foram analisadas revistas pedagógicas entre 1890 e 1930 a fim de investigar quais orientações eram sugeridas aos professores do ensino

\footnotetext{
69 Trata-se de pesquisa desenvolvida no âmbito do Programa de Pós-Graduação em Educação e Saúde na Infância e na Adolescência da UNIFESP, sob a orientação do Prof. Dr. Wagner Rodrigues Valente.

${ }^{70}$ Projeto Temático intitulado "A matemática na formação de professores e no ensino: processos e dinâmicas de produção de um saber profissional, 1890-1990" (VALENTE; BERTINI; MORAIS; PINTO; 2017), com financiamento da FAPESP. O projeto conta com financiamento da Fundação de Amparo à Pesquisa do Estado de São Paulo (FAPESP). Disponível em http://bv.fapesp.br/pt/auxilios/98879/a-matematica-na-formacao-deprofessores-e-no-ensino-processos-e-dinamicas-de-producao-de-um-saber-p/?q=17/15751-2

${ }^{71}$ Grupo de História da educação matemática no Brasil.
} 
primário para ensinar problemas de aritmética. As orientações dadas aos professores puderam ser categorizadas em cinco tendências: $1^{a}$ ) os problemas não eram temas de discussão nos artigos; $2^{\mathrm{a}}$ ) propostos como sinônimos de exercícios; $3^{\mathrm{a}}$ ) trabalho com os problemas era relacionado com os métodos modernos de ensino; $4^{\mathrm{a}}$ ) uma aritmética que ensinava problemas e não problemas a serviço da aritmética, e, finalmente, $5^{\mathrm{a}}$ ) os problemas seriam ensinados a partir dos Centros de Interesse ${ }^{72}$.

Essas tendências parecem ser apropriações do pensamento pedagógico disseminado no período, pois o como ensinar problemas aritméticos modifica-se na medida em que as ideias relacionadas ao método intuitivo, movimento da Escola Nova e os Centros de Interesse são disseminados.

Uma questão se coloca, frente aos resultados obtidos com a análise realizada por Souza (2017) é a de verificar a permanência dessas tendências em anos posteriores. Que saberes emergiam dos artigos para ensinar os problemas aritméticos? Para responder essas questões analisaremos a "Revista de Educação" em números publicados entre 1933 e 1943. A "Revista de Educação" organizada pela Diretoria do Ensino do Estado de São Paulo foi publicada entre 1933 e 1943. Nestes dez anos, foram 41 números em 30 volumes.

Figura 1: Capa da Revista de Educação $\mathrm{n}^{\circ} 3$ de setembro de 1933

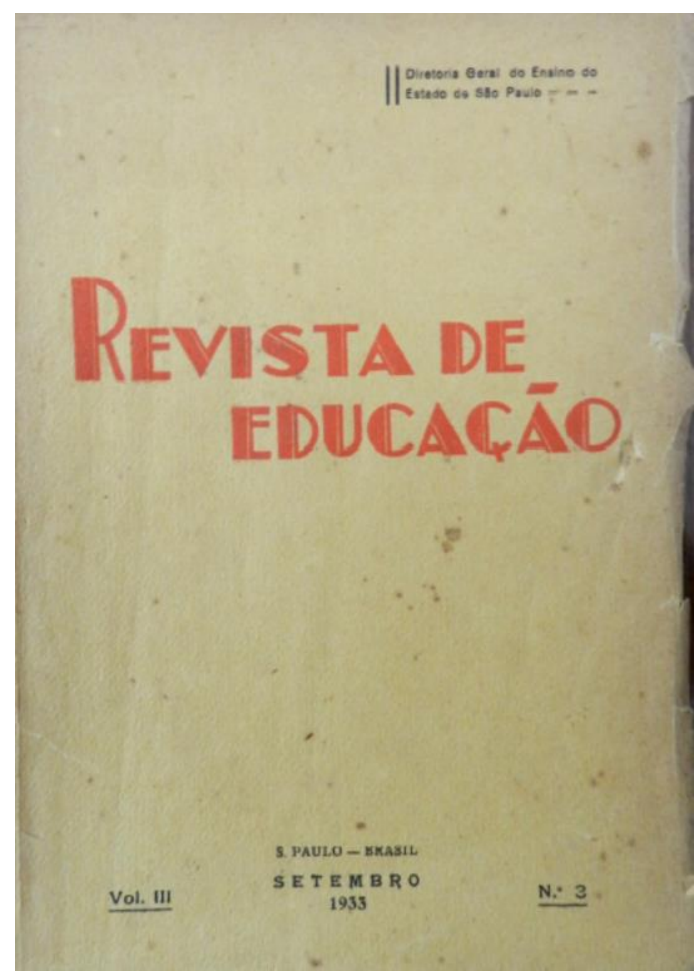

Fonte: Repositório de Conteúdo Digital da UFSC

\footnotetext{
${ }^{72}$ De acordo com Valdemarin (2010, p. 92), os centros de interesse determinam o "processo global e a relação de desenvolvimento e aprendizagem entre a criança e o ambiente, no qual, progressivamente são encontrados os elementos que dão acesso ao pensamento analítico".
} 
Inicialmente era gratuita e distribuída aos professores da rede pública, entretanto em seu último número faz menção de que seria reduzida a apenas um exemplar para cada biblioteca escolar devido à falta de recursos, o que talvez também tenha sido justificativa para o fim da publicação.

De acordo com MELLO (2007, p. 154) o cenário da Diretoria Geral do Ensino teve muitas trocas de diretor totalizando catorze no período da publicação da revista. Com estas mudanças a revista não teve um projeto unicamente direcionado, tendo publicado artigos dos mais diversos temas e com autores distintos, independentemente de suas visões sobre a educação.

Na busca pelos exemplares desta revista utilizamos o Repositório de Conteúdo Digital73 da Universidade Federal de Santa Catarina. Nele estão disponíveis 39 dos 41 números da revista. Os exemplares não estão completos, entretanto os artigos sobre aritmética estão disponíveis. Sintetizamos no quadro 1 os artigos encontrados.

Quadro 1: Relação dos artigos sobre ensino de aritmética

\begin{tabular}{|l|l|l|}
\hline Título do Artigo & Nome do Autor & \multicolumn{1}{c|}{ Informações da revista } \\
\hline $\begin{array}{l}\text { O ensino de } \\
\text { matemática }\end{array}$ & $\begin{array}{l}\text { Jose Ribeiro } \\
\text { Escobar }\end{array}$ & $\begin{array}{l}\text { Revista de Educação, 1934, v. V, n. 5, mar. SP } \\
\text { Disponível em: } \\
\text { http://repositorio.ufsc.br/xmlui/handle/123456789/99958 }\end{array}$ \\
\hline $\begin{array}{l}\text { Sobre a Didática } \\
\text { do cálculo }\end{array}$ & Renato Jardim & $\begin{array}{l}\text { Revista de Educação, 1934, v. VII, set., SP. } \\
\text { Disponível em: } \\
\text { http://repositorio.ufsc.br/xmlui/handle/123456789/99962 }\end{array}$ \\
\hline $\begin{array}{l}\text { O ensino da } \\
\text { taboada no } 2^{0} \\
\text { ano }\end{array}$ & $\begin{array}{l}\text { Luiz Gonzaga } \\
\text { Fleury }\end{array}$ & $\begin{array}{l}\text { Revista de Educação, 1936, v. 13/14, n. 13/14, mar./jun., SP. } \\
\text { Disponível em : } \\
\text { https://repositorio.ufsc.br/xmlui/handle/123456789/128339 }\end{array}$ \\
\hline Arithmetica & $\begin{array}{l}\text { João Alfredo de } \\
\text { Souza Oliveira }\end{array}$ & $\begin{array}{l}\text { Revista de Educação, 1936, v. 15/16, n. 15/16, set./dez., SP. } \\
\text { Disponível em: } \\
\text { http://repositorio.ufsc.br/xmlui/handle/123456789/99962 }\end{array}$ \\
\hline $\begin{array}{l}\text { O ensino de } \\
\text { artihmetica }\end{array}$ & $\begin{array}{l}\text { Renato de } \\
\text { Arruda } \\
\text { Penteado }\end{array}$ & $\begin{array}{l}\text { Revista Educação, 1937, v. XIX/XX, n. 19/20, set./dez., SP. } \\
\text { Disponível em: } \\
\text { https://repositorio.ufsc.br/handle/123456789/115835 }\end{array}$ \\
\hline $\begin{array}{l}\text { Didactica do } \\
\text { calculo }\end{array}$ & $\begin{array}{l}\text { Benedito } \\
\text { Caldeira }\end{array}$ & $\begin{array}{l}\text { Revista de Educação, 1940, v. XXVIII, mar./jun.-set./dez., } \\
\text { SP. } \\
\text { Disponível em: } \\
\text { https://repositorio.ufsc.br/handle/123456789/115826 }\end{array}$ \\
\hline
\end{tabular}

Fonte: Repositório de Conteúdo Digital da UFSC

Uma primeira observação é a de que segundo Mello (2007) dos artigos publicados na Revista de Educação trinta e cinco tratavam sobre a alfabetização. Nesta busca conseguimos seis artigos sobre o ensino de aritmética. Excetuamos desta tabela artigos com o foco na reprovação, programas de ensino, escola nova, questões para provas, pois a aritmética e o ensino de problemas apareceram de forma transversal, não sendo o principal objetivo desses artigos.

73 Disponível em https://repositorio.ufsc.br/handle/123456789/1769

ISSN 2526-2882 
De todos os autores o único que havia publicado artigos em outras revistas paulistas sobre o ensino de aritmética entre 1890 e 1930 foi José Ribeiro Escobar. No artigo "O ensino de matemática" publicado em 1934 o autor inicia argumentando em favor de uma didática para o ensino de matemática e enumerando diversos autores para justificar a beleza e a importância da matemática.

Critica os professores por tornarem essa ciência tão temida aos alunos e afirmava sua competência rememorando a época em que estava na Escola Normal de São Paulo. Escobar menciona autores para referenciar o ensino de matemática Kerschnsteiner, Montessori, Dewey, Paytot, pois posiciona-se contrário a todo “[...] exclusivismo pedagógico. Devemos acolher todas as orientações - alemã, francesa, americana, italiana ou russa - porque cada uma só percebe uma face do espírito, visando um só aspecto da educação.” (ESCOBAR, 1934, p.111).

Segundo Escobar os autores citados defendiam o ensino de matemática a partir dos trabalhos manuais, podendo assim a sala de aula ser transformada em uma sala-ambiente na qual tudo que interessaria ao ensino de matemática estivesse presente. Em seguida o autor aprofunda em conceitos da geometria, frações, ângulos, teoremas, afirma que os problemas tratados graficamente (utilizando desenhos/riscos para resolver) ganhariam maior nitidez para os alunos. Segundo o autor a criança deveria reproduzir os caminhos para a evolução da humanidade para tal cita autores da biologia, filosofia e psicologia tais como Serres, Rousseau, Pestalozzi, Comte e Spencer.

Escobar no subtítulo “A percepção e o raciocínio- a análise” defende o método analítico $^{74}$ como melhor marcha para ensinar. Justificando essa defesa cita Mercante e um exemplo de problema formulado por esse autor.

Para resolver problemas apresenta como questões auxiliares para o entendimento divididas entre induções e deduções podendo assim caminhar para a conclusão. Em seguida apresenta que para Mercante um problema composto teria cinco partes para analisar como mostra a figura 1.

Figura 2: Trecho do artigo de José Ribeiro Escobar

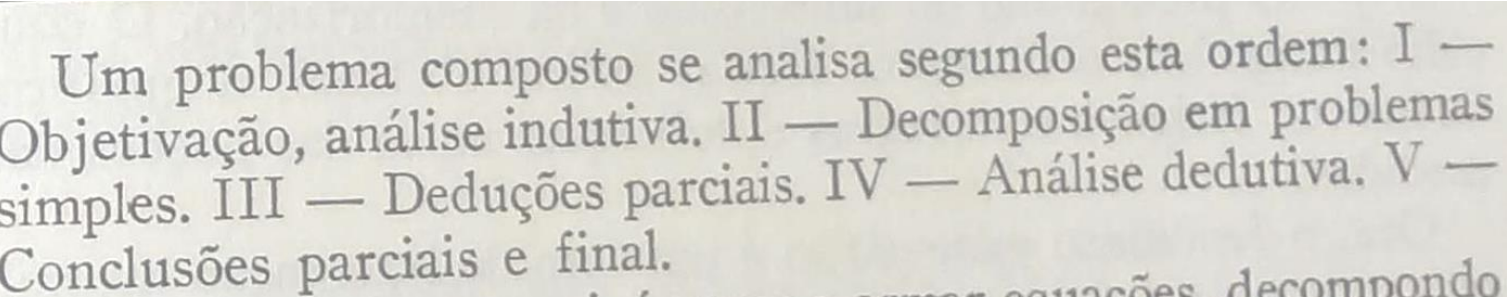

Fonte: Revista de Educação, março de 1934

74 O método analítico na alfabetização consiste em ensinar a ler e a escrever a partir de palavras, frases ou textos, ou seja, ensinar do todo para as partes.

$$
\text { ISSN 2526-2882 }
$$


Em certo momento o autor opta por narrar como se deu o processo de evolução no ensino de aritmética infantil, dividindo-o em quatro fases: $1^{\text {a }}$ ) predomínio do simbolismo e da memorização; $2^{\mathrm{a}}$ ) preceitos de Pestalozzi como do concreto para o abstrato, do fácil para o difícil, ensino intuitivo, privilegia a oralidade entre outros; $3^{\text {a }}$ ) o Método Grube ensinando os números como resultados das operações fundamentais; $4^{\mathrm{a}}$ ) o método psicológico publicado por Dewey e McLellan inicialmente indutivo para chegar a dedução a fim de fixar o conteúdo.

Nesse modelo, segundo Escobar, a trigonometria, por exemplo, poderia ser ensinada a partir de problemas e que fossem resolvidos inicialmente com a aritmética, para somente depois resolver utilizando a álgebra.

Novamente o autor menciona um outro problema de geometria proposto por Mercante e dois momentos para a resolução: indutivo e dedutivo. Mas nem só de manejo do professor sustentava-se a aprendizagem. A atenção, a vontade, o esforço do aprendiz também diferenciavam o tamanho do sucesso. A clareza, o poder de síntese para definir os pontos apresentados e o senso moral também eram considerados pontos chave para o ensino da disciplina, de acordo com o autor.

Observa-se nesse artigo que o saber profissional estava ancorado na multiplicidade de métodos pedagógicos advindo de diferentes autores. Caberia ao professor escolher dentre essa variedade levando em conta aspectos observados em seus alunos.

O segundo artigo intitulado "Sobre a didactica do calculo" escrito por Renato Jardim e publicado também em 1934, foi a transcrição de uma palestra proferida na Associação de Professoras. Jardim faz questionamentos a respeito das habilidades matemáticas serem distintivas entre as pessoas. Os que a possuem seriam vistos pela sociedade de forma diferente. O artigo conta com treze páginas das quais cerca de onze são dedicadas a memórias do tempo em que o autor era aprendiz, como por exemplo, de recitar a tabuada em todo início das aulas e de enunciar as belezas do pensamento matemático.

Quase ao final do artigo menciona a escola ativa, atividades globalizantes, centros de interesse, jogos e projetos como sendo uma alternativa para a "velha didática". Um questionamento levantado pelo próprio autor é o de como atender os programas por matérias e praticar o ensino globalizado. Responde que não tem solução, mas que poderia emergir de Calkins, Felix Klein, dos professores Escobar ou Ferraz de Campos ou ainda pelos jogos propostos pelas professoras D. Sylvia Guimarães ou D. Irene Muniz.

Nesse sentido Jardim pressupõe que o professor precisava inovar em sua sala de aula utilizando jogos, projetos, centros de interesse, contrapondo assim a "velha didática". Entretanto não poderia deixar de ensinar os conteúdos sugeridos nos programas de ensino, manuais escolares, provas e exames. 
Luiz Gonzaga Fleury tem publicado em 1936 seu artigo "O ensino de taboada no $2^{\circ}$ anno”. Inicia comentando que a Revista de Educação sofre críticas por serem teóricos e não práticos. Fleury afirma que ambos são importantes para o ensino, entretanto a partir dessa demanda a sugestão dos planos de aulas não seriam a favor de apenas mostrar "o que se deve fazer, mas como se faz".

Na sequência defende a tabuada de multiplicação como sendo a única que precisaria de fato ser memorizada. De antemão já argumentava que muitos professores ficariam horrorizados em ouvir sobre a memorização em tempos de escola ativa, métodos globais e aprendizagem motivada.

Para Fleury os métodos globais 75não ofereciam oportunidades suficientes para exercícios reiterados. Para tal afirmação cita Aguayo que acreditava que os exercícios não poderiam ser suprimidos das aulas pois mesmo não sendo a partir do interesse, eles faziam parte dos hábitos e atitudes mentais importantes e exigidos em um trabalho de boa qualidade.

Fleury apontava que os alunos no $1^{\circ}$ ano aprendiam a tabuada do $1,2,3,4$ e 5 e, portanto, ao iniciar o $2^{\circ}$ ano os professores deveriam retomar a tabuada do 4 com a finalidade de perceber possíveis dificuldades. De acordo com o autor muitas crianças não sabiam ainda o significado do sinal de multiplicação, portanto era necessário que na $1^{\mathrm{a}}$ aula demonstrassem que a multiplicação era uma adição de parcelas iguais. $\mathrm{Na} 2^{\mathrm{a}}$ aula os alunos iriam para o quadro negro e com a utilização de desenhos de cavalos iriam mostrar o que já sabiam sobre a tabuada do 4 por meio de uma disputa entre os alunos.

Até a $8^{\text {a }}$ lição a sequência é na primeira aula demonstrar os resultados da tabuada com adições de parcelas iguais e na segunda utilizar um desenho, automóvel, aeroplano para fazerem disputas entre os alunos avançando nas tabuadas. Também sugeria utilizar o tempo em casa para memorizar os fatores. No final da sequência restaria apenas ao professor ensinar a multiplicação por zero e por dez.

Fleury compreendia a teoria e a prática como ferramentas importantes para a constituição do saber profissional, entretanto deu ênfase ao "como se faz" sugerindo aos professores modelos. Defendia a importância da memorização e o treino dessa habilidade por meio dos exercícios, contrapondo assim o método global. Ao professor caberia seguir os modelos e investir em exercícios/repetições a fim de garantir a aprendizagem dos conteúdos.

75 Entendemos como método global o conjunto dos métodos analíticos, no qual ensina-se a partir do todo. Tendo a aritmética como foco, o professor poderia ensinar a partir dos problemas determinados conceitos diferentes do método sintético no qual primeiro eram apresentados os números, depois operações concluindo com a resolução de problemas. Esse método foi disseminado pelo psicólogo e educador Ovide Decroly. ISSN 2526-2882

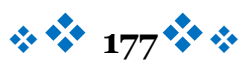


No quarto artigo publicado em 1936 intitulado “Arithmetica”, João Alfredo de Souza Oliveira iniciou trazendo a história das descobertas matemáticas como os algarismos, a invenção dos sinais, aspectos como número, quantidade e operações.

Nos últimos parágrafos deste artigo o autor define que "problema de cálculo é toda e qualquer questão para resolver números dados" (OLIVEIRA, 1936, p.51), considerava que a memória não seria a única via para a aprendizagem e a importância do contador mecânico para a compreensão das operações.

Enfatizava três partes importantes para o ensino de aritmética: $1^{\mathrm{a}}$ ) o cálculo mental $2^{\mathrm{a}}$ ) cálculo escrito $3^{\mathrm{a}}$ ) aplicação das operações em questões usuais ou a resolução de problemas. Defendia que durante o cálculo mental os problemas deveriam ser de natureza concreta. Finalizou o artigo com a seguinte afirmação:

Figura 3: Trecho do artigo de João Alfredo de Souza Oliveira

O professor deve dar especial attenção á resolução de problemas, porque é nella que se opera o emprego racional do calculo, mental ou escripto, dando origem, assim, á resposta satisfactoria.

Fonte: Revista da Educação, setembro/dezembro de 1936

Em síntese, Oliveira sugeria uma sequência na qual os professores iniciariam do mais simples, no caso o cálculo mental, passando pelo cálculo escrito até chegar aos problemas. A utilização de materiais didáticos era importante e a memorização não era anunciada como sendo principal via de aprendizagem.

Em “O ensino de artihmetica” escrito por Renato de Arruda Penteado publicado em 1937 o autor já iniciou argumentando quais seriam os objetivos para o ensino de aritmética segundo Charters: $1^{\circ}$ ) Hábito da precisão $2^{\circ}$ ) A rapidez e a segurança no cálculo $3^{\circ}$ ) $\mathrm{O}$ desenvolvimento da capacidade de raciocinar.

No hábito da precisão era importante que o aluno, para além de identificar a operação para elucidar o problema, conseguisse resolver a operação, pois a parte mecânica era tão importante quanto o raciocínio. Conquistada com o trato contínuo dos números, a rapidez e segurança no cálculo precisaria de mecanização depois de o aluno compreender as particularidades do conteúdo.

Defendia partir dos problemas pois na vida prática lançaríamos mão do cálculo quando teríamos um problema a resolver. Segundo Penteado a capacidade de raciocinar era um elemento crucial da disciplina aritmética desenvolvida a partir das leis psicológicas, ou seja, partir do particular para o geral, do concreto ao abstrato. 
Ainda enumerou alguns princípios básicos para o ensino como a observação, comparação, elaboração ou associação, abstração e generalização, e por último a aplicação, o que implicaria em um ensino inicialmente intuitivo passando para o indutivo-dedutivo.

A motivação também seria outro elemento para o ensino de aritmética, para tal feito apresentar problemas que se apresentassem na vida escolar ou no cotidiano seria importante diferentemente de problemas cheios de elementos que jamais utilizariam.

Sobre os conteúdos a serem ensinados, Penteado cita Thorndike ${ }^{76}$ para justificar o ensino de números, quatro operações, sistema métrico, relações entre medidas, frações, leitura de diagramas e símbolos, resolução de problemas simples sobre áreas e volumes, porcentagem e juros. A partir disso advoga em favor dos programas de ensino que segundo Penteado estariam bem organizados a partir dessa lógica.

Ao professor caberia dosar o ensino, preconizando inicialmente os valores/conteúdos para depois aplicá-los em problemas. Para o ensino de números, o autor defendia o método Grube como ainda sendo o melhor para os iniciantes. Novamente defendeu a utilização de problemas desde a primeira aula. Concluiu afirmando que sendo utilizados esses preceitos o ensino de aritmética nos quatro anos primários perderia sua aridez e desenvolveria melhor os alunos. Após a conclusão o autor cita a bibliografia utilizada, até então uma novidade nos artigos de aritmética.

Figura 4:Trecho do artigo de Renato de Arruda Penteado

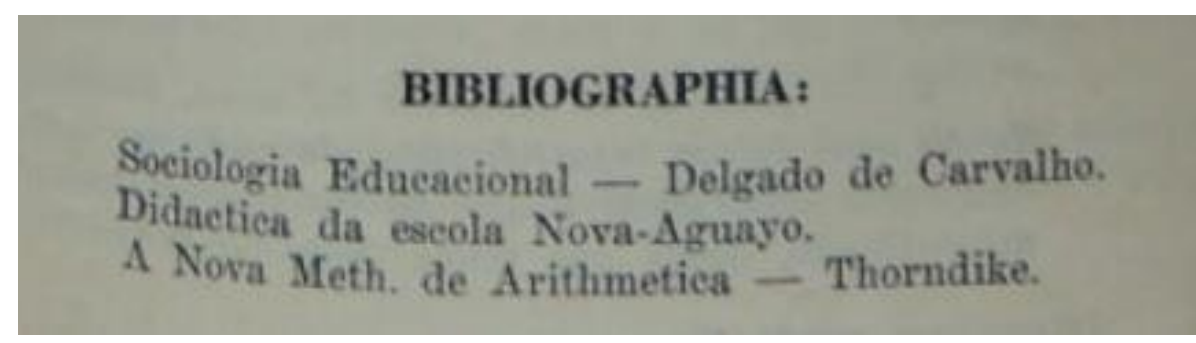

Fonte: Revista de Educação, setembro e dezembro de 1937

Ao que parece, para Penteado, um bom professor seria aquele que possuísse conhecimentos em relação ao que se discutia em âmbito pedagógico/psicológico e fizesse apropriações desses saberes mesclando-os com a experiência docente.

O último artigo escrito por Benedito Caldeira intitula-se "Didática do Cálculo" publicado em 1940. O artigo parecia atender a uma demanda proposta a Delegacia Regional de Ensino no qual precisariam ser elucidados algumas questões do ensino.

\footnotetext{
${ }^{76}$ De acordo com Rezende (2016) é possível identificar nesse artigo de Penteado apropriações das obras de Thorndike em relação aos objetivos principais do ensino de aritmética. ISSN 2526-2882 
Dedicou o primeiro ponto do artigo para tratar sobre o cálculo, que segundo ele era uma dificuldade que assoberbava a tarefa do professor. Para ele a dificuldade estaria na excessiva concretização para a criança, o abandono do treino das operações, a "mania raciocinante" como citava Backheuser, o raciocínio em equação como citava Ferraz de Campos e o exagero do método Grube.

Cita Claparede, Hunt, Thorndike, McLellan, Klapper, Aguayo, Comas, Euclides Roxo, Backheuser, Melo e Souza, Alda Lodi e Cecil Thiré afim de mostrar ao leitor certa profusão de autores de seu conhecimento.

Menciona o Programa do Distrito Federal (na época Rio de Janeiro) em que tomando conceitos de Thorndike, as leituras suplementares de Melo e Souza e Irene de Albuquerque tornou-se "um vade-mecum" para os professores. Nos centros de exercícios, propostos por Thorndike as operações partiam de temáticas do dia a dia como compra de doces, notas, material escolar, pesagem, horário escolar, compras a prestações, construção e plantas de casas entre outros. Utilizou as fases psicológicas de Backheuser para mostrar modificações possíveis para o programa de ensino.

Defendia o uso do concreto, seja ele nos objetos ou ainda com pauzinhos na quadronegro e sugeriu a utilização da "Árvore do Cálculo". Concordava que ainda nas escolas o método Grube insistia em ensinar as quatro operações juntas, entretanto, outros autores já recomendavam que cada operação tinha um processo/raciocínio e por isso cada qual teria um tempo de aprendizagem. Só depois de os alunos aprenderem a agrupar elementos e estariam aptos a aprender tabuadas pelo contador ou pelos tornos. A partir deste momento alguns exercícios e jogos seriam feitos com a finalidade inicial de entender a multiplicação e de memorizar os resultados.

Cita Mercante no que tange a resolução de problemas apesar de criticar o modo como o Mercante pensava a criança, Caldeira acha interessante o modo como ele organiza a forma de ensinar os problemas, respeitando quatro passos: objetivação, indução, dedução e conclusão.

Justificou sua opinião pelo contexto em que Mercante escreveu o livro, na época não havia tantos avanços na psicologia infantil. Reafirma que os problemas precisariam estar ligados ao cotidiano, portanto justificava-se os centros de exercícios que estavam postos no programa de matemática do distrito federal.

Caldeira utiliza Aguayo para caracterizar os problemas em tipologias diferentes tais como: práticos, narrativos, contos aritméticos, de situação real, sem números, incompletos e propostos pelos alunos.

Os problemas não deveriam ser “quebra-cabeças, sendo os mais reais possíveis e não seria adequado diversos problemas em uma única aula. Concluiu o artigo argumentando em 
favor desses preceitos para o ensino de aritmética que derivavam de sua experiência no ensino primário.

Com a leitura desse artigo era possível que para Caldeira os saberes profissionais poderiam ser constituídos a partir de ampla base teórica, assim o professor poderia fazer escolhas de acordo com seu público. Percebe-se que um fator de grande importância era a valorização dos estudos psicológicos.

\section{Ensino de problemas e os saberes profissionais: considerações parciais}

Nesses seis artigos foi possível perceber diferentes nuances entre os autores em relação ao ensino dos problemas aritméticos.

Enquanto Fleury (1937) para o ensino da tabuada não propôs a utilização de problemas, os demais autores afirmam ser de grande importância os problemas nas aulas de aritmética.

Apesar de defender a escola ativa e o método globalizante Jardim (1934) não trazia sugestões de como os problemas poderiam aparecer em um contexto no qual equiparar as propostas inovadoras com os programas de ensino era um desafio.

Escobar (1934) utiliza Mercante para falar dos problemas nas aulas de aritmética e não fez críticas a este autor, em contrapartida Caldeira (1940) afirmava que a lógica para a resolução de problemas apesar de ser interessante não respeitava as fases infantis, muito menos as recentes descobertas da psicologia infantil.

Caldeira (1940) afirmava que o método Grube não era indicado aos alunos iniciantes, discordando do posicionamento de Penteado (1937) que era a favor. Tanto Oliveira (1936) quanto Penteado (1937) concordavam que as aulas deveriam ter os problemas, mas nos parece que pelos passos apresentados pelos autores, os problemas seriam um refinamento do pensamento servindo para aplicar as operações.

Outro ponto a destacar é o de que dos seis autores, três se identificaram como sendo diretores de grupos escolares do interior de São Paulo (OLIVEIRA, 1936; PENTEADO,1937; CALDEIRA,1940), um era Chefe do serviço de Educação Primária da Diretoria de Ensino (FLEURY,1937), Renato Jardim tinha sido diretor da Escola Normal da Capital e José Ribeiro Escobar atuou na Reforma Carneiro Leão. Todos eram representantes do Governo do Estado de São Paulo.

Como já citado anteriormente as trocas de diretor da Diretoria de Ensino potencializaram o aparecimento de artigos com visões antagônicas estivessem presentes na "Revista de Educação” (MELLO, 2007, p.154).

Souza (2018) observa que nas revistas entre 1890 e 1930 dos 35 artigos que citam problemas apenas dois autores de artigos citam autores de referência, sejam eles filósofos, 
pedagogos e/ou psicólogos. Nestes seis artigos pudemos ver a pluralidade de autores utilizados sejam para argumentar em favor ou contra o que o artigo objetivava.

Mas voltando ao título deste item: que saberes essa revista contemplava para o ensino de problemas aritméticos? Em uma mesma revista na qual diferentes pontos de vista eram sugeridos pelos autores dos artigos, os argumentos utilizados seriam um diferencial para a disseminação de seus modelos.

O professor que tivesse acesso aos estudos da pedagogia e da psicologia, compreendesse os processos de mudanças enfrentado pelo ensino de aritmética no qual passase de uma pedagogia tradicional, para o método intuitivo defendido por Pestalozzi, passando ao método Grube e chegando ao método psicológico de McLellan e Dewey (ESCOBAR,1934) poderia construir um posicionamento com maior embasamento científico.

É possível que neste momento o professor para ensinar aritmética, utilizando os problemas, precisaria de saberes profissionais construídos no âmbito das Ciências da Educação, em outras palavras tomar posse das descobertas sobre o desenvolvimento infantil para reorientar suas escolhas e práticas docentes

Saber em que momento propor problemas, com qual objetivo, que perguntas fazer, como mediar para que os alunos conseguissem resolvê-los, manter a atenção e a motivação não poderia ser algo constituído apenas pelos saberes produzidos na e pela matemática.

\section{Referências}

CALDEIRA, B. Didactica do calculo. IN: Revista de Educação, 1940, v. XXVIII, mar./jun.set./dez., SP. Disponível em: https://repositorio.ufsc.br/handle/123456789/115826

ESCOBAR, J. R. O ensino de matemática. IN: Revista de Educação, 1934, v. V, n. 5, mar. SP. Disponível em: http://repositorio.ufsc.br/xmlui/handle/123456789/99958

FLEURY, L. G. O ensino da taboada no $2^{\circ}$ anno. IN: Revista de Educação, 1936, v. 13/14, n. 13/14, mar./jun., SP. Sisponível em https://repositorio.ufsc.br/xmlui/handle/123456789/128339

\section{HOFSTETTER, R; SCHENEUWLY, B. Saberes: um tema central para as profissões do} ensino e da formação. In: HOFSTETTER, Rita.; VALENTE, Wagner Rodrigues. (org.). Saberes em (trans) formação: tema central da formação de professores. $1^{\mathrm{a}}$ ed. São Paulo: Editora Livraria da Física, 2017.

JARDIM, R. Sobre a didática do calculo. IN: Revista de Educação, 1934, v. VII, set., SP. Disponivel em: http://repositorio.ufsc.br/xmlui/handle/123456789/99962

MELLO, M. C. de O. A alfabetização na imprensa periódica educacional paulista (1927-1943). 2007. 239 f. Tese (Doutorado em Educação) - Faculdade de Filosofia e Ciências, Universidade Estadual Paulista, Marília, 2007. Disponível em: 
https://www.marilia.unesp.br/Home/PosGraduacao/Educacao/Dissertacoes/mello _mco_dr_mar.pdf

OLIVEIRA, J. A. S. Arithmetica. IN: Revista de Educação, 1934, v. VII, set., SP. Disponível em: http://repositorio.ufsc.br/xmlui/handle/123456789/99962

PENTEADO, R. A. O ensino de arithmetica. IN: Revista Educação, 1937, v. XIX/XX, n. 19/20, set./dez., SP. Disponível em: https://repositorio.ufsc.br/handle/123456789/115835

\section{REZENDE, A.M.S. Apropriações de teorias de Edward Lee Thorndike para o ensino} dos saberes elementares matemáticos em revistas pedagógicas brasileiras. São Cristóvão, 2016. 98 f. Dissertação (Mestrado em Ensino de Ciências e Matemática) - Universidade Federal de Sergipe, 2016. Disponível em: https://repositorio.ufsc.br/handle/123456789/173285

SOUZA, A. F. Discursos sobre problemas aritméticos (São Paulo, 1890-1930). Guarulhos, 2017. 135 f. Dissertação (Mestrado) - Universidade Federal de São Paulo, Escola de Filosofia, Letras e Ciências Humanas, 2017. Disponível em: https://repositorio.ufsc.br/xmlui/handle/123456789/178612

Os problemas de aritmética e as transformações no saber profissional do professor que ensina matemática, 1890-1990. In: XXII Encontro Brasileiro de Estudantes de Pós-Graduação em Educação Matemática, 2018, Belo Horizonte. Anais, Belo Horizonte: Universidade Federal de Minas Gerais, 2018. Disponível em: <http://sbem.iurioo94.hospedagemdesites.ws/eventos/index.php/EBRAPEM/2018

VALDEMARIN, V. T. História dos Métodos e Materiais de Ensino: A Escola Nova e Seus Modos de Uso. Editora Cortez. São Paulo. 2010.

VALENTE, W.R. Processos de investigação histórica da constituição do saber profissional do professor que ensina matemática. Acta Scientiae, v.20, n.3, maio/jun. 2018 Disponível em: http://www.periodicos.ulbra.br/index.php/acta/article/view/3906

\section{Biografia Resumida}

Andreia Fernandes de Souza: Graduada em Educação Artística e Pedagogia. Mestre em Ciências pela UNIFESP. Doutoranda pela UNIFESP no Programa de pós-Graduação em Educação e Saúde a Infância e Adolescência. Professora das séries iniciais na rede pública de São Paulo. Integrante do GHEMAT/UNIFESP.

Link Lattes: http://Link Lattes.cnpq.br/3191293621023301

e-mail: deianandes@hotmail.com

ISSN 2526-2882 